\title{
Karakteristik Morfogenetik Ayam Kokok Balenggek Di Kecamatan Tigo Lurah Kabupaten Solok
}

\author{
Firda Arlina, Dasmi Ahmad, Tinda Afriani, Lany Madina \\ Fakultas Peternakan Universitas Andalas
}

\begin{abstract}
The study was aimed to define the morphogenetic characteristics of native song fowl chickens of West Sumatra called Kokok Balenggek. Sixty Kokok Balenggek chickens raised by farmers in Tigo Lurah sub district, Solok district were used as samples. They consisted of 40 males and 20 females. Both qualitative and quantitative morphogenetic data were collected and measured, including: color of feather and shank; form of comb; length of tars metatarsus, tibia, femur; body weight and distance between pelvis bone by females. By males, feather color of Kokok Balenggek chickens were dominated by wild feather type (e+) and silver (S) of $42,5 \%$ and $22,5 \%$, respectively. Comb were mostly single form (90\%). While feather color of females were dominated by black (S) and white (25\% each), pea comb (90\%), shank color of white yellow (Id) (85\%). Length of metatarsus for male and females of 100,2 $\pm 11,05 \mathrm{~mm}, 80,03 \pm 8,64 \mathrm{~mm}$; tibia of 134,40 \pm 18,73 and $117,14 \pm 10,24 \mathrm{~mm}$; femur of 103,36 $\pm 16,94$ and $85,63 \pm 11,47 \mathrm{~mm}$; body weight of $1,74 \pm 0,46 \mathrm{~kg}$ and $1,11 \pm 0,62 \mathrm{~kg} / \mathrm{head}$, respectively. Data of distance length between pelvis bone by females were found $41,17 \pm 4,32 \mathrm{~mm}$.
\end{abstract}

Key word : Kokok Balenggek chickens, morphogenetic characters.

\section{Pendahuluan}

Ayam lokal sebagai asset nasional yang keberadaanya sudah tersebar dari sabang sampai Merauke merupakan komoditi utama ternak asli Indonesia dan merupakan sumber daya genetik unggas Indonesia yang perlu dipertahankan keberadaannya. Ayam lokal Indonesia yang mempunyai ciri-ciri khusus telah beradaptasi dengan baik pada lingkungannya sehingga membentuk kelompok - kelompok sendiri, dikenal dengan ayam kampung, ayam pelung, ayam kedu dan ayam Kokok Balenggek.

Ayam Kokok Balenggek merupakan ayam lokal (asli) Sumatera Barat yang berkembang di kecamatan
Payung Sakaki, Kabupaten Solok Sumatera Barat. Ayam Kokok Balenggek tergolong ayam penyanyi (song fowl) dengan suara kokok yang merdu dan bertingkat. Ayam ini ditetapkan sebagai maskot Kabupaten Solok. Dan merupakan salah satu jenis ternak yang mendapatkan perhatian tinggi dalam keberadaan dan pengembangannya. Meskipun memiliki potensi yang cukup tinggi jumlah ayam Kokok Balenggek jantan di daerah ini relative sedikit. Populasinya sekitar 354 ekor (Abbas dkk, 1997). Populasi ini sangat rawan akan kepunahan.

Kelebihan suara yang di miliki Ayam Kokok Balenggek ini menjadikan ayam ini berbeda dengan ayam kampung lainnya. Keunikan 
ayam ini telah menjadi perhatian banyak penggemar ayam hias, bahkan putra mahkota Jepang Pangeran Akisihino datang berkunjung ke Sumatera Barat untuk mendengarkan kemerduan suara Ayam Kokok Balenggek dan menyaksikan dari dekat keberadaan Ayam ini (Haluan, Agustus 1994). Sekarang Ayam Kokok Balenggek menjadi satwa endemik yang merupakan fauna maskot Kabupaten Solok (Rusfidra, 2001 a, Rusfidra 2001 b).

Keterbatasan plasma nutfah ini adalah semakin banyaknya yang dijual atau dibawa keluar daerah yang menyebabkan populasinya menurun. Populasi Ayam ini di daerah asalnya tinggal \pm 350 ekor dari 29.000 ekor populasi ayam di centra produksi Abbas dkk, (1987). Disamping itu dengan terbukanya daerah ini dari isolasi transportasi diduga ayam ini sudah mengalami penurunan dalam irama kokok yang bertingkat. Bahkan menurut penduduk lanjut usia dulu banyak ditemukan yang mencapai 19 lenggek lebih.

Ayam Kokok Balenggek yang dipelihara mempunyai kombinasi warna bulu yang elok, cantik dan menarik, bentuk jengger dan warna shank/cakar yang tidak jauh berbeda dengan ayam kampung, yang istimewa pada Ayam Kokok Balenggek terletak pada kombinasi suara yang menarik.

Nozawa (1980) melaporkan bahwa keragaman ukuran tubuh hewan disebabkan oleh faktor genetik dan lingkungan. Ukuran tubuh ayam yang penting untuk diamati dan dapat dijadikan penentu karakteristik antara lain bobot badan, panjang tarsometatarsus, panjang tibia, panjang femur, tinggi jengger dan jarak antara tulang pelvis untuk ayam betina.

Untuk mempertahankan sumber daya genetik yang dimiliki dan sebagai peluang pelestarian dan pengembangan Ayam Kokok balenggek, sangat diperlukan data dasar tentang karakteristik genetik eksternal untuk sifat - sifat kualitatif dan kuantitatif seperti ukuran ukuran tubuh sehingga memudahkan kita untuk pengembangan ayam ini dari segi pemuliaan.

Mengingat potensi ekonomi dan kelangkaan Ayam Kokok Balenggek ini dan informasi genetik yang masih kurang maka sangat perlu dilakukan penelitian mengenai karakteristik genetik eksternal ayam kokok balenggek, dalam rangka menunjang program konservasi plasma nutfah.

\section{Materi Dan Metode}

Penelitian ini menggunakan sampel 60 ekor Ayam Kokok Balenggek yang terdiri dari 40 ekor jantan dan 20 ekor betina. Umur ayam \pm 30 minggu dan sudah dewasa kelamin yang di Kecamatan Tigo Lurah Kabupaten Solok, Sumatera Barat. Alat yang digunakan adalah timbangan dengan kapasitas $5 \mathrm{~kg}$ dan alat ukur jangka sorong.

Metode penelitian adalah metode survey yang dilakukan melalui pengamatan secara langsung pada usaha Peternakan Ayam Kokok Balenggek di Kecamatan Tigo Lurah Kabupaten Solok. Pengumpulan data dilakukan dengan mengamati secara langsung karakteristik morfogenetik baik sifat kualitatif maupun kuantitatif. Untuk sifat kualitatif Ayam Kokok Balenggek peubah yang diamati meliputi :

1. Warna bulu
a. Putih (I); Warna bulu putih dominan


b. Hitam (E); Warna bulu hitam dominan

c. Keperakan (S); Warna bulu putih keperakan yang bersifat sex - linked.

d. Emas (s); Warna bulu emas keperakan yang bersifat sex linked.

e. Bar (B); Warna bulu belang hitam putih yang bersifat sexlinked.

f. Bulu liar (e+); Warna bulu merupakan campuran hitam dan coklat; biru dan merah.

g. Columbian (e); Warna bulu putih kecuali bagian leher, sayap dan ekor berwarna hitam atau merah.

2. Bentuk jengger

a. Pea (P); Berbentuk ercis (riginya pendek dan tebal)

b. Tunggal (pp); Bentuknya berdiri tegak, pipih dan terbagi seperti gergaji.

c. Walnut (W)

d. Rose (r)

3. Warna kulit kaki /Shank

a. Kuning/putih (1d); Shank/ cakar berwarna kuning atau putih polos.

b. Hitam (id) = Shank/cakar berwarna hitam abu - abu atau hijau polos.

Untuk karakteristik morfogenetik untuk sifat kuantitatif peubah yang diukur adalah :

1. Panjang femur atau tulang paha $(\mathrm{mm})$. Pengukuran dimulai dari persendian yang menghubungkan antara tulang panggul dengan tulang paha.

2. Panjang tibia atau tulang kering $(\mathrm{mm})$. Pengukuran dimulai dari persendian yang menghubungkan antara tulang paha dengan tulang kering

3. Panjang tarsometatarsus atau panjang tulang kaki (mm).
Pengukurannya dimulai dari persendian yang menghubungkan tibia dengan tarsometatarsus hingga persendian yang menghubungkan antara tarsometatarsus dengan shank (cakar)

4. Jarak antara tulang pelvis ( $\mathrm{mm})$. yaitu jarak yang diukur mulai dari ujung tulang panggul bagian kanan arah kedalam sampai tulang panggul bagian kiri.

5. Bobot badan $(\mathrm{kg})$

Data yang di peroleh kemudian dikelompokkan berdasarkan jenis kelamin untuk sifat kualitatif dihitung berdasarkan persentase. Untuk parameter karakteristik genetik eksternal kuantitatif dilakukan analisis statistik diskriptif dengan menghitung mean, dan simpangan baku.

\section{Hasil Dan Pembahasan}

\section{Karakter Genetik Eksternal Kualitatif Ayam Kokok Balenggek}

Hasil penelitian terhadap sifat kualitatif ayam Kokok Balenggek dapat kita lihat pada Tabel 1. Pada Tabel 1 dapat kita lihat bahwa warna bulu ayam Kokok Balenggek yang banyak ditemukan adalah tipe bulu liar (e+) sebanyak 17 ekor (42,50\%), hal ini disebabkan oleh karena ayam Kokok Balenggek mewarisi sifat kualitatif dari nenek moyangnya ayam hutan merah. Sesuai dengan pendapat Mufarid (1990) nenek moyang ayam lokal Indonesia adalah ayam hutan merah dan ayam hutan hijau, ayam hutan merah banyak hidup disekitar hutan - hutan di Sumatera Barat. Sedangkan Hutt (1949) menyatakan bahwa salah satu ciri - ciri dari ayam hutan merah adalah pada bagian leher, sayap, 
punggung bewarna merah dan bagian dada sebelah dalam bewarna hitam.

Tabel 1. Jumlah dan Persentase Sifat Kualitatif Ayam Kokok Balenggek

\begin{tabular}{lllrrrr}
\hline \multirow{2}{*}{ No } & \multirow{2}{*}{ Peubah } & \multirow{2}{*}{ Fenotipe } & \multirow{2}{*}{ Genotipe } & \multicolumn{3}{c}{ Jenis Kelamin } \\
\cline { 5 - 7 } & & & Jantan $(\%)$ & Betina (\%) \\
\hline 1. Warna bulu & Tipe bulu liar & e+ & $17(42,50)$ & $2(10,00)$ \\
& & Warna perak & $\mathrm{S}$ & 9 & $(22,50)$ & $4(15,00)$ \\
& & Warna emas & $\mathrm{S}$ & 6 & $(15,00)$ & $1(5,00)$ \\
& & Bar & $\mathrm{B}$ & 3 & $(7,50)$ & $2(10,00)$ \\
& & Non bar & $\mathrm{bb}$ & 3 & $(7,50)$ & $2(10,00)$ \\
& & Colombian & $\mathrm{e}$ & 1 & $(2,50)$ & \\
& & Putih & $\mathrm{I}$ & 1 & $(2,50)$ & $5(25,00)$ \\
& & Hitam & $\mathrm{E}$ & & - & $5(25,00)$ \\
\hline 2. & \multirow{2}{*}{ Bentuk Jengger } & Tunggal & $\mathrm{p}$ & 36 & $(90,00)$ & $4(20,00)$ \\
& & Pea & $\mathrm{P}$ & 4 & $(10,00)$ & $16(80,00)$ \\
\hline 3. & Warna shank & Kuning/putih & $\mathrm{Id}$ & 36 & $(90,00)$ & $17(85,00)$ \\
& & Hitam & id & 4 & $(10,00)$ & $3(15,00)$ \\
\hline
\end{tabular}

Tabel 2. Rataan dan Simpangan Baku Karakter MorfoGenetik untuk Sifat Kuantitatif Ayam Kokok Balenggek

\begin{tabular}{llcc}
\hline \multirow{2}{*}{ No } & \multicolumn{2}{c}{ Peubah yang Diamati } & \multicolumn{2}{c}{ Rataan dan Simpangan Baku } \\
\cline { 3 - 4 } & & Jantan & Betina \\
\hline 1. & Panjang tarsometatarsus $(\mathrm{mm})$ & $100,20 \pm 11,05$ & $80,03 \pm 8,64$ \\
2. & Panjang tibia $(\mathrm{mm})$ & $134,40 \pm 18,73$ & $117,14 \pm 10,24$ \\
3. & Panjang femur $(\mathrm{mm})$ & $103,36 \pm 16,94$ & $85,63 \pm 11,47$ \\
4. & Bobot badan $(\mathrm{kg})$ & $1,74 \pm 0,46$ & $1,11 \pm 0,62$ \\
5. & Jarak antara tulang pelvis & & $41,17 \pm 4,32$ \\
\hline
\end{tabular}

Sedangkan bentuk jengger yang dominan adalah bentuk tunggal (p) $90 \%$ pada jantan, hal ini erat kaitannya dengan asal usul ayam Kokok Balenggek yang berasal dari ayam hutan merah. Hutt (1949) menyatakan sebagian besar ayam piaraan yang ada sekarang ini memiliki bentuk jengger tunggal kemudian Mulyono dan Pangestu (1996) menyatakan bahwa bentuk jengger ayam kampung umunya berbebtuk tunggal dalam proses domestikasi ada perubahan bentuk jengger pada ayam. Warna shank dominan adalah warna kuning/putih
$90 \%$ pada jantan dan $85 \%$ pada betina.

\section{Karakter Genetik Eksternal Sifat} Kuanrtitatif Ayam Kokok Balenggek

Hasil pengamatan terhadap karakter genetik eksternal untuk sifat kuantitatif ayam Kokok Balenggek dapat dilihat pada Tabel 2.

Dari Tabel 2 didapatkan rata-rata panjang tarsometarsus pada ayan Kokok Balenggek jantan dan betina $100,20+11,05 \mathrm{~mm}$ dan $80,03+8,64$ $\mathrm{mm}$. Hasil penelitian ini lebih rendah dibandingkan dengan dengan hasil penelitian Mansjoer dkk (1989) pada ayam kampung dimana panjang tarsometatarsus $131,8 \mathrm{~mm}$ dan 
penelitian Mulyono dan Pangesrtu (1996) terhadap ayam Pelung 120,13

Tabel 3. Jenis Ayam Kokok Balenggek Berdasarkan Warna Bulu mm. Perbedaan ukuran - ukuran ini disebabkan oleh karena adanya perbe-

\begin{tabular}{lll}
\hline No & Jenis Ayam Kokok Balenggek & Jumlah dan Persentase \\
\hline 1. & Kinantan & $1(2.50)$ \\
2. & Taduang & $17(42.50)$ \\
3. & Jalak & $9(22.50)$ \\
4. & Biriang & $9(22.50)$ \\
5. & Kuriak & $4(10.00)$
\end{tabular}

Note: Angka dalam kurung adalah persentase

daan faktor genetik atau keturunan yaitu genotipe induknya dan perbedaan makanan dan lingkungan. Sesuai dengan pendapat Nishida dkk (1982) yang menyatakan bahwa keragaman ukuran tubuh ternak disebabkan oleh faktor genetik dan lingkungan.

Panjang tibia ayam Kokok Balenggek jantan dan betina $134,40 \pm$ $18,73 \mathrm{~mm}$ dan $117,14 \pm 10,24$. Hasil penelitian ini lebih tinggi dari hasil penelitian Khas (2001) terhadap ayam kampung dimana panjang tibianya $130,31 \mathrm{~mm}$ dan 113,63 $\mathrm{mm}$ dan lebih rendah dari hasil penelitian Mansjoer dkk (1989) dan Mulyono dan Pangestu (1996) terhadap ayam kampung dengan panjang tibia $159,33 \mathrm{~mm}$ dan $153,98 \mathrm{~mm}$. Sedangkan panjang femur ayam Kokok Balenggek jantan dan betina adalah 103,36 $\pm 16,94$ dan $85,63 \pm 11,47$, hasil ini juga lebih tinggi dibandingkan dengan hasi penelitian Khas (2001) 93,47 dan $82,91 \mathrm{~mm}$.

Jenis Ayam Kokok Balenggek yang banyak ditemukan adalah jenis taduang dimana warna taduang adalah mempunyai warna dasar hitam dan diselingi warna merah pada sayap ekor dan punggung. Murad (1989) banyaknya jenis warna ini ditemukan karena Ayam kokok balenggek masih mewarisi sifat kualitatif ayam hutan yang mempunyai warna dasar seperti jenis taduang ini.

\section{Kesimpulan}

Dari hasil penelitian dapat disimpulkan bahwa warna bulu ayam Kokok Balenggek jantan yang banyak adalah warna tipe bulu liar $(\mathrm{e}+)$ bentuk jengger tunggal (p) dan warna kulit kaki putih/kuning (Id) dan betina warna hitam (E) dan putih (I), bentuk jengger Pea $(P)$, warna kulit shank putih/kuning (Id). Sedangkan untuk karakter morfogenetik masih beragan dan keragaman tertinggi pada panjang tibia dan femur.

\section{Daftar Pustaka}

Abbas, M.H, A. Arifin, S.Anwar, A.Agustar, Y.Heryandi dan Zedril.1997. Studi Ayam Kokok Balcnggck di Kecamatan Payung Sakaki, Kabupaten Solok: Potensi Wilayah dan Genetik. Laporan Penelitian Pusat Pengkajian P'clernakan dan P'crikanan. Fak. Peternakan Universitas Andalas. Dinas Peternakan Sumatera Barat. Padang.66p. 
Haluan.21 juli 1993, Satu-satunya didunia yang ada Ayam Kokok Balenggek hanyalah di tempat Payung Sakaki Solok. Harian Haluan. Padang.

Hutt, F.B.1949. Genetik of the Fowl, Mc Crraw - Hill Book Company - inc. New York, Toronto, London.

Mansjoer, I., S.S Mansjoer dan B. Sayuti. 1989. Studi Banding Sifat-sifat Biologis ayam Kampung, ayam Pelung dan ayam Bangkok. Lembaga Penelitian IPB, Bogor S.P. Waluyo dan S.N Priyono. 1993. Perkembangan Berbagai Jenis Ayam Asli Indonesia. Fakultas Peternakan IPB. Bogor.

Mufarid, H. 1990. Beternak Ayam Hutan. Penebar Swadaya, Jakarta.

Mulyono, R dan R.B Pangestu. 1996. Analisis Statistik Ukuranukuran Tubuh dan Analisis Karakter-karakter Genetik eksternal pada Ayam Kampung, Pelung dan Ayam Kedu. Fakultas Peternakan IPB Bogor.

Murad,I. 1989. Ayam Yungkilok (Payung Sakaki Solok); Ayam Penyanyi Yang Sudah Langka dlan Mengarah Kepunahan (Artikel no 1). Padang.
Natawidjaja, A.G dan K.Dwiyanto. 1986. Status dan $\mathrm{Ke}$ mungkinan Pengembangan Ayam Bukan ras (Buras) di Kabupaten Gunung Kidul Ilmu dan Peternakan BPT, 2 : 123127.

Nozawa, K. $1980 . \quad$ Phylogenetic Studies of Native Domestic Animal in East and Southeast Asia. Tropical Agriculture Research Centre. Japan !v : $24-43$.

Rusfidra.2001 a. Konservasi Sumber Daya Genetik Avam Kokok Balenggek di Sumatera Barat. Makalah di Sampaikan Pada Seminar Nasional Bidang Ilmu Hayati. Tanggal 20 September 2001. Pusat Studi Ilmu Hayati Institut Pertanian Bogor.

Rusfidra 2001 b. Model Agribisnis Terpadu Berbasis Ayam Kokok Balenggek Untuk Ketahanan Pangan Rumah Tangga Petani di Sumatera Barat. Makalah ini disertakan Pada Lomba Karya Tulis Ilmiah Dalam Rangka Dies Natalis ke-38. Tgl 1 September 2001. Bogor.

Soedirdjoadmojo. 1984. Beternak Ayam Kampung Sebagai Usaha. BP Karya Tani. Jakarta.

\section{Alamat korespondensi: Ir. Firda Arlina, MSi \\ Jurusan Produksi Ternak Fakultas Peternakan Universitas Andalas Kampus Limau Manis Padang}

Diterima: 3 Januari 2007, Disetujui: 25 Januari 2007 